\title{
Review of Compression Properties of Coral Sands
}

\author{
Binbin $\mathrm{Xu}^{1, \mathrm{a}}$ and $\mathrm{Wei} \mathrm{Si}^{2, \mathrm{~b}}$ \\ ${ }^{1}$ Tianjin Port Engineering Institute Ltd. of CCCC, Tianjin, China; Key Lab. of Geotechnical \\ Engineering of Tianjin, Tianjin, China; Key Lab. of Geotechnical Engineering, Ministry of \\ Communication, Tianjin, China \\ 2 Tianjin Port Engineering Institute Ltd. of CCCC, Tianjin, China \\ axubinbin@tpei.com.cn, bsiwei@tpei.com.cn
}

\begin{abstract}
Keywords: Coral sand, Siliceous Sand, Compression behavior, Critical state
Abstract. The compressibility properties of coral sands have been realized from indoor experiments and in-site construction. In order to summarize the compressibility of coral sands, this paper reviewed the previous researches and gave some reference for the following researches. It is found that: 1) the compression curve of coral sand is very similar to that of normally consolidated clay and there are two parts of the curve, arc part and linear part; 2) The slope coefficient of the linear part becomes larger as the initial void ratio of the coral sand increases and all of them lies into the same final state as long as the compress stress is large enough.
\end{abstract}

\section{Introduction}

Since the special physical properties of coral sand have been addressed enough emphasis in the last several decades, the compression behavior of the coral sands have been researched by many researchers and the differences between siliceous sands are also noticed. The basic proper of coral sands grasp the emphasis of engineer with the development of the first drill holes of petroleum in Arabian Gulf, and it is the first time that the calcareous sedimentary deposit is mentioned in the literature. But because there is not any engineering experience in such kind of sand, the relative research was not enriched by this opportunity. Until 1968, during the construction of Lavan oil platform, a pile with $1 \mathrm{~m}$ diameters suddenly dropped around $15 \mathrm{~m}$ after going through a $8 \mathrm{~m}$ well-cementation ground and the much difference between coral sand and siliceous sand began to be realized.

Due to the long-term transport during the sedimentation, the coral sands keep the soil skeleton with tiny void, which results in the special mechanical properties such as inner void, irregular shape, low strength and easy to break. When carrying out conventional experiments, the coral sands exhibits quite different characteristics from land sands.

In this paper, the compression experimental results in the previous literatures are reviewed to instruct the following research and construction. A typical difference between these two sands is the particle strength; a silica particle requires extremely high pressure for crushing, while coral sand particles are highly susceptible to breakage or crushing, even under very low pressure. This feature will result in significant differences in their fundamental behavior, especially the compression behavior.

\section{Compression Properties}

The research results of Coop[1] show that there is similar compression behavior between coral sands and clay. If the vertical pressure overpassed certain value, the particle breakage controls the compressibility characteristics of coral sand. The consolidation properties are influenced by the percentage of calcium carbonate, cement degree and sedimentary period. The research shows that the higher the percentage of calcium carbonate is, the lower the rebound value is; the longer the sedimentary period is, the greater the strength is and the smaller the compressibility is. The cement degree of coral sand is related with the surrounding environment of the hydrological geology, which also influences the compressibility of coral sands to some extent. Liu[2] found that the 
compressibility of coral sands in China is very similar to normally consolidated clay. The compression index is a little larger than that of clay while the swelling index of coral sands is much smaller than that of clay. During the compression process, the deformation is almost plastic with very little elastic deformation.

The significant compressibility of coral sands is usually ascribed to the particle breakage during compression. According to the micro-structure research, the coral sands exist mainly in the shape of edges and a corner, which makes the effective contact area among particles less and under the same pressure, the contact stress among particles are much larger than other sands, which leads to particle breakage. The experimental results demonstrates that the compression index of coral sand is around 100 times of that of siliceous sands and it is determined by the particles' own strength. Compared with siliceous sands, the stiffness of coral sand is lower and there are inner void and irregular shape. The larger the inner void is, the larger the compressibility is. Figure 1 gives the compression curves of coral sand under isotropic condition. As can be seen, the compression property of coral sand is similar to that of normally consolidated clay while it is different from that of land sand. If the pressure is large enough, the same final state will be reached even though the initial void ratios of coral sands are different.

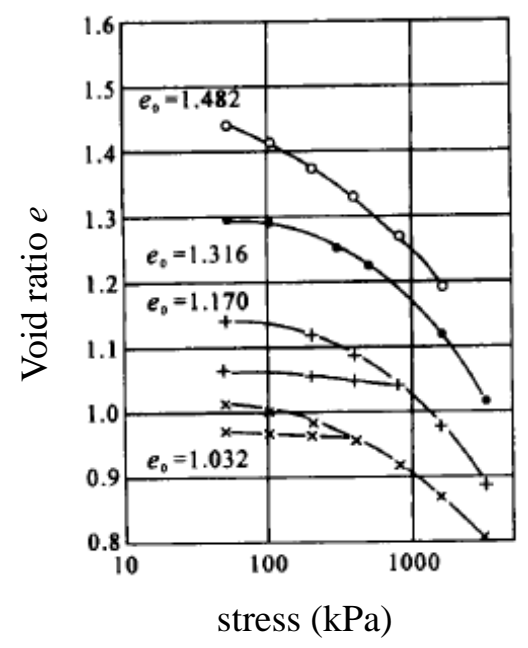

Figure 1 Compression behavior of coral sand with various initial void ratio

From the three-dimensional compression curve, there is basically similar compression tendency compared with one-dimensional compression curve. The curve is composed of gently arc part at the initial stage and quasi-linear part. At the arc part, the curvature increases as the stress becomes large. And in the quasi-linear part, the slope of the line is influenced by the initial void ratio. The larger the initial void ratio is, the steeper the slope is, which reflects that the larger the initial void ratio is the higher the compressibility of the coral sand is. For the one-dimensional compression curve, the intersection between the arc part and linear part is $800 \mathrm{kPa}$ while the intersection is $1600 \mathrm{kPa}$ for the three-dimensional compression curve. According to Nauroy's research[3], the compression index of the coral sand reaches limited values when the mean effective stress is around $500 \sim 800 \mathrm{kPa}$. Therefore, it is suggested that the limited compression index is defined as the slope coefficient of one-dimensional compression curve at $800 \mathrm{kPa}$. It can also be seen that the unloading-reloading curves are linear for both one-dimensional and three-dimensional curves and the two lines matches each other very well, which means that the compression deformation is mainly irrecoverable and plastic.

Figure 2 compares triaxial isotropic compression tests on Toyoura siliceous sand[4, 5], Goodwyn Coral sand[6] and Dogs Bay coral sand[1] in void ratio and mean effective stress space. Those samples are uncemented, freshly deposited and tested up to very high pressures. 


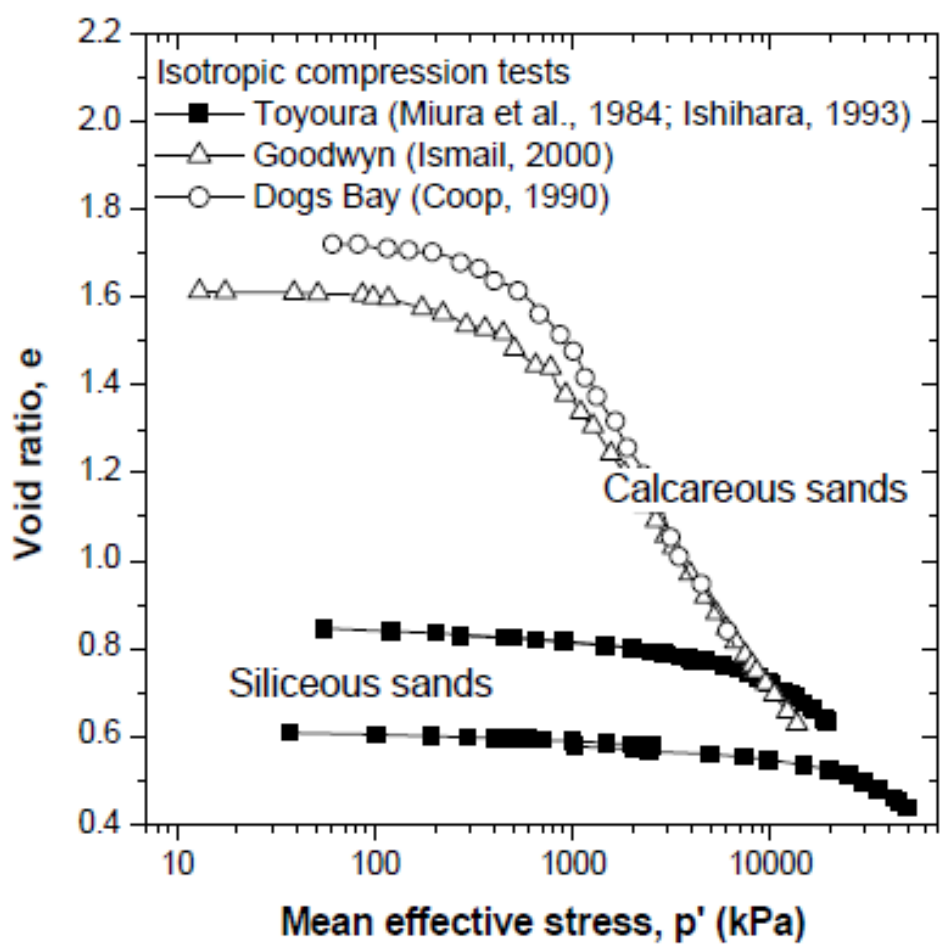

Figure 2 Consolidation curves for siliceous and coral sands

It is observed that the curves for Toyoura sand samples with two different initial densities eventually tend to merge into a unique asymptotic line as the stress level increases. The principal mechanism of this phenomenon involves particle crushing, while volume change at low stress level is due to rearrangement of the particles themselves[7]. Pestana and Whittle[8]described this convergent state as a limiting compression curve(LCC). Its uniqueness has to be confirmed, though, for both one-dimensional loading conditions and isotropic compression $[9,10]$.

The compression behavior of coral sands is significantly different from siliceous sands. The initial void ratios of Goodwyn and Dogs Bay sands are very high but their relative densities are similar to the loose samples of Toyoura sand. Then, the results show significant non-linear volumetric reduction over a wide range of stress, independent of the initial density. This is due to the loose contracts between particles and fragile angular grains with excessive intra-particle voids [11]. Such high compressibility is the most distinctive feature of coral sand. The interpretation of compression behavior is one of the most significant aspects for the selection of physical properties or the development of suitable constitutive models.

\section{Influence Factors of Particle Breakage}

As mentioned above, the most obvious characteristics of the coral sand is particle breakage, that is during the compression process, the grain composition varies. Because the main compositions of the coral sand are calcite and aragonite, whose strength is much smaller than siliceous, there will be particle breakage even under very low stress level. The breakage of coral sand during the shear process is much different from rock damage, the reason of which lies in the high contact stress among the particles to make the particle breaking and smooth. There are many factors influencing the particle breakage, such as composition of grain, stress level, grain distribution, relative density and shape of particles.

In order to evaluate the particle breakage qualitatively, many classifications of particle breakage have been proposed, in which the method proposed by Guyon and Troadec[12] is most practical and scientific. According to the breakage modes, the particle breakage can be divided into three types, as shown in Figure 3. The first type is fracture, where the particle breaks into several small particles with similar size; The second type is attrition, where the particle breaks into one a bit larger particle and 
several smaller particles; The third one is abrasion, where the size of particle keeps almost unchanging and the surface is abraded into micro-particles. Under the condition of compression, the first two types are most common for spherical-shape particles while the third type occupies predominately under the shear condition.

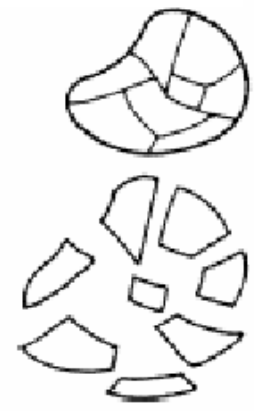

(a)

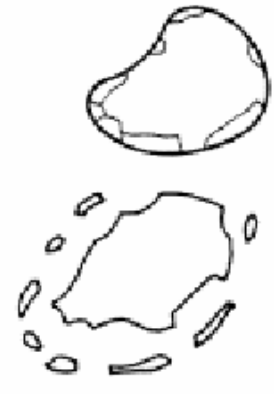

(b)

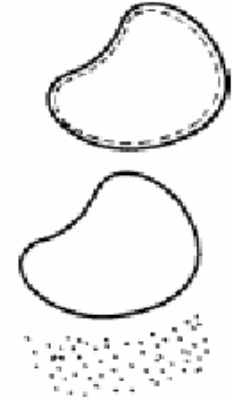

(c)

Figure 3 Types of particle breakage

\section{Conclusions}

The most obvious properties of coral sand is particle breakage. The compression behavior and the particle breakage are mutually influenced for the mechanical property of coral sand. In this paper, the compression property of coral sand is reviewed and the comparison to the siliceous sand is also shown according to previous research. The conclusions are as follows:

1) The compression curve of coral sand is quite similar to that of normally consolidated clay. It is composed of arc part and linear part.

2) The larger the initial void ratio is, the steeper the compression curve is. As long as the compression stress is large enough, the coral sand would reach the same final state and it can be called critical state.

\section{References}

[1] M.R. Coop: Geotechnique, Vol. 40-4, (1990), p. 607.

[2] C.Q. Liu: Rock and Soil Mechanics Vol. 19-1 (1998), p. 32.

[3] J.F. Nauroy: Conference on Geotechnical Practice in Offshore Engineering, Australia, Texas, April, (1983), p.356.

[4] N. Mirua, H. Murata and N. Yasufuku: Soils and Foundations, Vol 24-1, (1984), p. 77.

[5] R. Verdugo and K. Ishihara: Soils and Foundations, Vol. 36-2, (1996), p. 81.

[6] M.A. Ismail: PhD thesis, University of Western Australia, Australia (2000).

[7] J.E. Roberts and J.M. DeSouza: Proceedings ASTM, Vol. 58, (1958), p.1269.

[8] J.M. Pestana and A.J. Whittle: Geotechnique, Vol.54-4, (1995), p.611.

[9] M.R. Coop and I.K. Lee: Proc. C.P. Wroth Memorial Sysposium, Thomas Telford, London, (1993), p.186.

[10] H.A. Joer, M.D. Bolton and M.F. Randolph: Inter. Workshop on Soil Crushability IWSC, Yamaguchi, Japan, (2000).

[11] M.R. Coop and D.W. Airey: Characterisation and Engineering Properties of Natural Soils, Vol. 2, Singapore, Balkema, Rotterdam, p.1049.

[12] E. Guyon and J.P. Troadec: Editions Odile JACOB Science, (1994). 